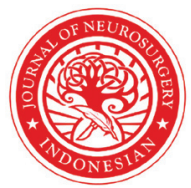

Indonesian Journal of Neurosurgery

\section{Ponticulus posticus upon routine evaluation of cervical spine x-ray in head injury patient: Case reports}

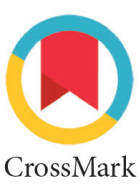

\author{
Farid Yudoyono ${ }^{1,2 *}$, Christian Ade $^{2}$
}

\title{
ABSTRACT
}

${ }^{1}$ Neurospine and Pain Center, Santosa Hospital Bandung Kopo, Bandung,Jawa Barat, Indonesia;

2Department of Neurosurgery, Faculty of Medicine, Universitas Padjadjaran, Bandung, Jawa Barat, Indonesia;

*Corresponding author: Farid Yudoyono;

Department of Neurosurgery, Faculty of Medicine, Universitas Padjadjaran, Bandung, Jawa Barat, Indonesia; faridspine@gmail.com

Received: 2021-06-15 Accepted: 2021-10-26

Published: 2021-12-03
Introduction: Ponticulus posticus or known as foramen arcuate is an anatomic variation of the first cervical vertebra origin from calcification of the posterior atlantooccipital membrane. The vertebral artery passes through this canal. This canal can be complete or incomplete and can also be unilateral or bilateral. Often related to symptoms of headaches, vertebrobasilar insufficiency, or acute hearing loss. Whereas, imaging studies show the presence of a partial osseous bridge on the upper surface of the atlas. This study aimed to present two cases of ponticulus posticus in head injury patients.

Case presentation: We reported 2 cases of ponticulus posticus found incidentally in head injury patients at our institution. The patients were managed conservatively for 5 days and sent home with no neurological deficit and complication.

Conclusion: Ponticulus posticus is often ruled out in pre-admission screening. Neurosurgeons should consider this to predict the neurological deficit.

Keywords: foramen arcuate, head injury, ponticulus posticus, posterior atlantooccipital membrane.

Cite This Article: Yudoyono, F., Ade, C. 2021. Ponticulus posticus upon routine evaluation of cervical spine x-ray in head injury patient: Case reports. Indonesian Journal of Neurosurgery 4(3): 103-105. D0I: 10.15562/ijn.v4i3.162

\section{INTRODUCTION}

Ponticulus posticus is an anatomic variant of the first cervical vertebral and associated with the vertebral arteries. Incidental findings are commonly visualized from lateral cervical plain X-rays taken for routine neurosurgery examination. Ponticulus posticus in Latin means small posterior bridge. ${ }^{1}$ The overall incidence of ponticulus posticus has been reported as $16.7 \%$, with more incidence occurring higher in women compared to men., ${ }^{2,3}$ There are variations seen in imaging study according to Miki et al. which are partial, total, and calcified forms of ponticulus posticus. ${ }^{3}$ As a result of the ossification of posterior atlanto-occipital, arcuate foramen develops in which vertebral artery and the back branch of $\mathrm{C} 1$ spinal nerve passes through (Fig. 1). ${ }^{4}$

Based on data from a meta-analysis by Elliott et al., ${ }^{5}$ the frequency of ponticulus posticus was found in $18.8 \%$ of post mortem examinations, $17.2 \%$ of computed tomography (CT) scans, and $16.6 \%$ of radiographic examinations. Most patients who have ponticulus posticus have no symptoms. The emergence of clinical signs of vertebrobasilar insufficiency develops only in $5.5 \%$ of patients in the case of cyclical strangulation that forms in the area of the osseous ring anomaly. ${ }^{6}$

This bone bridge often contributes to neck pain or chronic headaches, migraine, dizziness, shoulder pain, or some form of orofacial pain. Maxillofacial surgeons have reported surgical significance during the management of atlantoaxial stability for atlas fixation. During neuro intervention, pedicle screw insertion can cause injury to the vertebral artery and suboccipital nerve. It can cause reduced blood circulation and headaches after surgery. Surgeons who are experts in such cases recommend using modified screw passages to avoid piercing the vertebral arteries and closely related structures. Casual movement such as flexion and neck extension or continuous trauma in people with arcuate foramen can suppress and limit the movement of the vertebral artery. ${ }^{7,8}$

There are several reports dedicated to the treatment of compression syndrome in patients with these anomalies. Most of the reports discussed conservative treatment. $^{8,9}$ Meanwhile, the previous study noted that there were recurrence

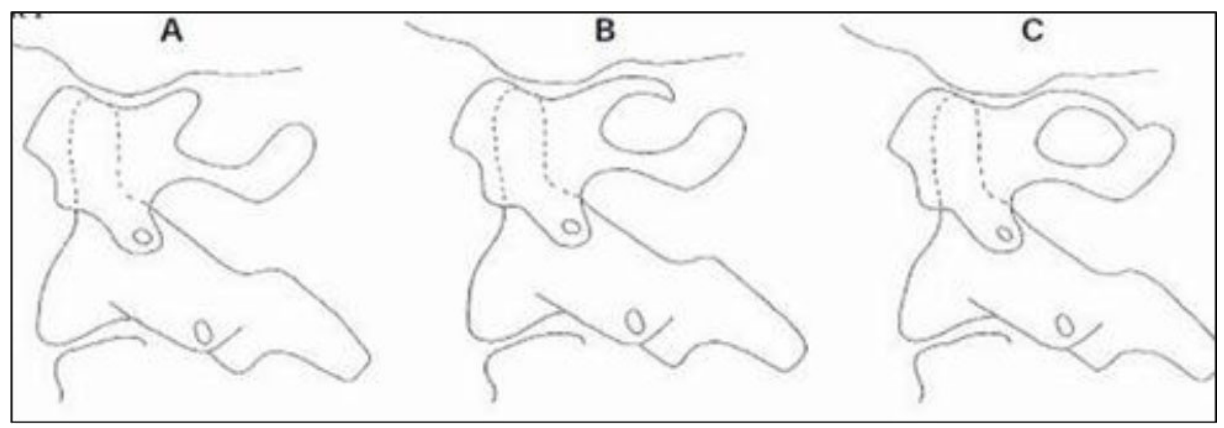

Figure 1. The forms of the vertebral sulcus. A. Normal sulcus vertebralis. B. Partial arcuate foramen. C. Total arcuate foramen 
symptoms that often occur in $50-60 \%$ of patients, who need a repeat treatment course. Only a few journals described the surgical treatment of Kimmerle's anomaly, which is the posterior midline approach to decompress the vertebral artery at the V3 segment. Regression of clinical signs of vertebrobasilar is observed in $90 \%$ of patients who are operated on..$^{6,10-14}$

\section{CASE PRESENTATION}

\section{Case 1} motorcycle in a high-velocity collision with another motorcycle from the opposite. He experienced posterior neck pain but no neurological deficit. His pain improved with physical therapy and oral medications. Deep tendon reflexes in both upper and lower extremities were normal and symmetrical with no pathological reflexes. Head CT scan was within normal limit and cervical spine radiographs revealed diffuse complete arcuate foramen on $\mathrm{C} 1$ (Fig. 2A).

\section{Case 2}

The patient was a 34-year-old male with a chief complaint of a decrease of consciousness after suddenly falling during riding a motorcycle. He complained of headache and posterior neck pain. However, no other neurological deficit was found. Headache was improved with medication. Neck pain persisted
The patient was a 27 -year-old male riding

for about 2 months and improved with physical therapy and analgesic. Deep tendon reflexes in both upper and lower extremities were normal and symmetrical with no pathologic reflexes. Head CT scan was within normal limit and cervical spine radiographs revealed diffuse complete arcuate foramen on C1 (Fig. 2B).

\section{DISCUSSION}

The vertebral arteries enter through the arcuate foramen, namely through the osseous fissure arch, potentially causing periodic disturbances in arterial blood flow and the phenomenon of suppression in the periarterial sympathetic plexus, especially during rotation, flexion, and expansion of head movements and cervical curves. The result of this disorder is induction of the transient phenomenon of vertebrobasilar insufficiency or symptoms that resemble Barre-Lieou syndrome. Furthermore, is characterized by traumatic or osteoarthritic degeneration in the third and fourth cervical vertebrae, which results in impaired blood circulation which induces symptoms from cranial nucleus projections, especially cerebral conjugations V and VIII. These symptoms are not only cervical pain, headaches that are focused on the occipital part, ringing in the ears (tinnitus), visual disturbances, loss of consciousness, vasomotor disturbances on the face, and disorders of swallowing and phonation, but there can also be

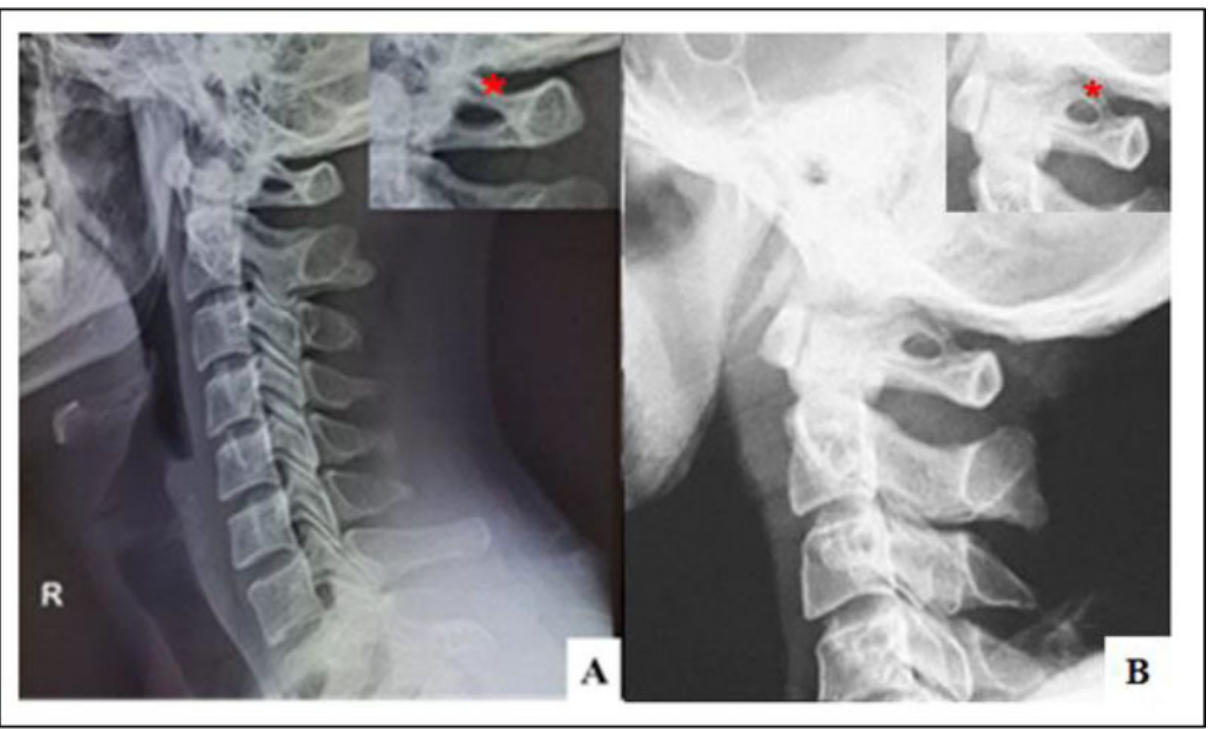

Figure 2. A. Case 1. B. Case 2. Cervical lateral radiograph shows complete type arcuate foramen (red asterisk). episodes of depression and anxiety as well as memory and attention difficulties. ${ }^{15,16}$

There are several studies that show that knowledge of the presence or absence of variations in the anatomy of the atlas is important during the planning of neurosurgery operations related to the craniovertebral junction. Therefore, vertebral arteries have a risk of injury during surgery with a posterior approach to the craniovertebral junction area such as lateral dissection and C1 decompression laminectomy or other stabilization procedures such as inserting screws into the lateral mass of the atlas. This latter procedure is widely used for the management of atlantoaxial instability. ${ }^{17,18}$

Vascular injury during surgery can be a cause of massive bleeding and can cause cerebral arterial blood flow to decrease. Early recognition of specific anatomic areas including the presence of arcuate foramen can reduce the risk of vertebral artery injury during surgery at the craniovertebral junction. ${ }^{19}$ In addition, a potential relationship between anatomic variations in the atlas and the onset of acute hearing loss has also been investigated. This can be associated with functional disorders in the occipitocervical junction area, in the form of hypermobile or hypomobile atlantooccipital articulation. ${ }^{20-22}$

Clinical and radiological findings in this case indicate a possible relationship between ponticulus posticus and the emergence of chronic tension-type headaches. The only abnormal findings during the investigation are complete arcuate foramen on the surface of the superior atlas and loss of normal cervical curvature. The relationship between headaches and arcuate foramen has been thoroughly investigated in the past, showing that this anatomic variation can be a cause of cervicogenic headaches and migraines. The mechanism of induction of these symptoms is potentially analogous to those mentioned above, namely transient ischemic compression of the vertebral artery during its journey through the arcuate foramen and/or increased tension in the dura mater in the occipitocervical junction area. $^{23}$ 


\section{CONCLUSION}

Ponticulus posticus is often ruled out. Clinical manifestations can differ in both severity and symptoms experienced by patients. Pre-admission cervical $\mathrm{x}$-ray screening is important for the presentation of this anomaly and to detect vertebrobasilar insufficiency.

\section{CONFLICT OF INTEREST}

There is no competing interest regarding the manuscript.

\section{FUNDING}

None.

\section{AUTHOR CONTRIBUTION}

All of the authors equally contribute to the study from the case selection, data gathering, and data analysis until interpreting the case study outcome through publication.

\section{REFERENCES}

1. Chitroda PK, Katti G, Baba IA, Najmudin M, Ghali SR, Kalmath B, Vijay G. Ponticulus posticus on the posterior arch of atlas, prevalence analysis in symptomatic and asymptomatic patients of Gulbarga population. J Clin Diagn Res. 2013; 7(12): 3044 - 7. https:// doi.org/10.7860/JCDR/2013/6795.3847.

2. Hasan M, Shukla S, Siddiqui MS, Singh D. Posterolateral tunnels and ponticuli in human atlas vertebrae. J Anat. 2001; 199(Pt 3): 339 - 343. https://doi.org/10.1046/j.14697580.2001.19930339.x.

3. Huang DG, Hao DJ, Fang XY, Zhang XL, He BR, Liu TJ. Ponticulus posticus. Spine J. 2015; 15: 17-19.

4. Aktas A, Erkmen C, Ozdol C, Parpar T, Ustun ED, Gurses C, et al. Variations of sulcus arteria vertebralis and correlation with clinical symptoms. J Clinical Analytical Med. 2016; 157: $830-4$.

5. Elliott RE, Tanweer O. The prevalence of the ponticulus posticus (arcuate foramen) and its importance in the Goel-Harms procedure: Meta-analysis and review of the literature. World Neurosurg. 2014; 82(1-2): e335 - 43. https://doi. org/10.1016/j.wneu.2013.09.014.

6. Lutsik AA, Peganov AI, Kazantsev VV, Ratkin IK. Vertebrobasilar insufficiency due to osseous abnormalities of the craniovertebral junction. Hir Pozvonoc. 2016; 13(4): 49 - 55. https://doi. org/10.14531/ss2016.4.49-55.

7. Schilling J, Schilling A, Galdames IS. Ponticulus posticus on the posterior arch of atlas, prevalence analysis in asymptomatic patients. Int J Morphol. 2010; 28(1): 317 - 22.

8. Malhotra K, Liebeskind DS. Duplicated origin of vertebral artery. Neurol India. 2017; 65(3): 679 - 80. https://doi.org/10.4103/neuroindia. NI_1080_16.

9. Gulyaev SA, Kulagin VN, Arkhipenko IV, Gulaeva SE. Clinical manifestations and treatment for Kimmerle anomaly. RMJ. 2013; 16: $866-8$

10. Buna M, Coghlan W, deGruchy M, Williams D, Zmiywsky O. Ponticles of the atlas: A review and clinical perspective. J Manipulative Physiol Ther. 1984; 7(4): $261-6$.

11. Tedeschi G. Surgical trial in the vertebral flow alteration due to Kimmerle anomaly. $J$ Neurosurg Sci. 1979; 23(3): 235 - 8.

12. Chertkov AK, Klimov ME, Nesterova MV. On surgical treatment of patients with vertebrobasilar insufficiency associated with Kimmerle anomaly. Hir Pozvonoc. 2005; 1: 69 73. https://doi.org/10.14531/ss2005.1.69-73.

13. Limousin CA. Foramen arcuale and syndrome of Barre-Lieou. Its surgical treatment. Int Orthop. 1980; 4(1): 19 - 23. https://doi. org/10.1007/BF00266599.

14. Split W, Sawrasewicz-Rybak M. Character of headache in Kimmerle anomaly. Headache. 2002; 42(9): 911 - 916. https://doi.org/10.1046/ j.1526-4610.2002.02213.x.

15. Barsukov SF, Grishin GP. The vertebrobasilar blood circulation of the brain in the presence of Kimmerle's anomaly. Voenno-Meditsinskii Zhurnal. 1991; 6: $42-45$.

16. Tubbs RS, Shoja MM, Shokouhi G, Farahani RM, Loukas M, Oakes WJ. Simultaneous lateral and posterior ponticles resulting in the formation of a vertebral artery tunnel of the atlas: Case report and review of the literature. Folia Neuropathol. 2007; 45(1): 43 - 46.

17. Cho YJ. Radiological analysis of ponticulus posticus in Koreans. Yonsei Med J. 2009; 50(1): 45 - 49. https://doi.org/10.3349/ ymj.2009.50.1.45.

18. Young JP, Young PH, Ackermann MJ, Anderson PA, Riew KD. The ponticulus posticus: Implications for screw insertion into the first cervical lateral mass. J Bone Joint Surg Am. 2005; 87(11): 2495 - 2498. https://doi.org/10.2106/ LBJS.E.00184.

19. Senoglu M, Yakup G, Yuksel KZ, Uzel M, Celik $\mathrm{M}$, Ozbag D. The effect of posterior bridging of $\mathrm{C}-1$ on craniovertebral junction surgery. $J$ Neurosurg Spine. 2006; 5(1): 50 - 52. https://doi. org/10.3171/spi.2006.5.1.50.

20. Sprekelsen MB, Hormann K, Weh L. Sudden hearing loss and the cranio-cervical junction. An Otorrinolaringol Ibero Am. 1990; 17(4): 353368 .

21. Cakmak O, Gurdal E, Ekinci G, Yildiz E, Cavdar $\mathrm{S}$. Arcuate foramen and its clinical significance. Saudi Med J. 2005; 26(9): 1409 - 1413.

22. Wight S, Osborne N, Breen AC. Incidence of ponticulus posterior of the atlas in migraine and cervicogenic headache. J Manipulative Physiol Ther. 1999; 22(1): 15 - 20. https://doi. org/10.1016/s0161-4754(99)70100-4.

23. Koutsouraki E, Avdelidi E, Michmizos D, Kapsali S-E, Costa V, Baloyannis S. Kimmerle's anomaly as a possible causative factor of chronic tension-type headaches and neurosensory hearing loss: Case report and literature review. Int J Neurosci. 2010; 120(3): 236 - 9. https://doi. org/10.3109/00207451003597193.

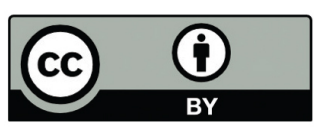

This work is licensed under a Creative Commons Attribution 